\title{
Technology and Language Learnings: Use of Social Network for Academic Purpose
}

\author{
Reena Mittal
}

\begin{abstract}
The present paper is a study to showcase the use of social networking sites for students. Here I have tried to put the uses and misuses of these sites along with the advantages of these social networking sites. They have been introduced in some countries in mainstream but across the world we all are not only using them but have become dependent on them to some extent. No doubt, they expanded the horizons of knowledge, sharing information and creative ideas and make our reading global. But I as teacher have to teach our students about the proper and adequate use of these social networking sites. We are also familiar with the after myths these sites are creating. Also some new social networking sites have been suggested for the convenience of the students apart from the popular ones.
\end{abstract}

Index Terms-Websites, apps, technology, students, connection.

\section{INTRODUCTION}

In today's world, it isn't what you know but rather what you can know - and how fast you can know something new. Technology is a non-negotiable tool in the process and a competitive advantage in terms of the speed at which we access that which is new. In this way, technology brings new opportunities to access information, to create rich technology-based environments where students experience new and challenging things, and to connect students which new and different people, places, and things. Technology can take us to places we have never been nor are likely to ever go. Technology can connect us with people around the world who offer different perspectives and experiences. These opportunities will result in many types of learning. It is up to classroom teachers, instructional designers, and program developers - essentially every individual involved in education - to ensure that these technology - facilitated opportunities benefit learning and every child's future.[1]

\section{TECHNOLOGY AND LEARNING}

Technology transcends knowledge faster than any other mode of teaching. Present era need no boundaries for the spread of knowledge and sharing of ideas and creativity. Social networking brings distances closer and people more approachable. There was a time when we heard news from $\mathrm{BBC}$ once is a while and feel elevated. But now we can share

Manuscript received December 28, 2017; revised February 20, 2018.

Dr. Reena Mittal is with D.A.K. Degree College, Moradabad, UP 244001 India (e-mail: mittal.reena23@gmail.com). all the news, information globally instantly as and when they happen. These features are really helpful in spreading and sharing knowledge. Using technology for mainstream has become a very in trend. Many people (teachers and students both) are using it for many years. Facebook has popularized social networking sites and now they have become indispensable part of life. The paper focusses on the uses and misuses of these sites and their impact on students. There sites were started for communication purposes over for places and globally but we embraced them to get online connection $24 \times 7$ with our peers family and friends. We share information, our ideas and knowledge and showcase our social and personal life too. [2] I am the mother of a 25 year old and his interest in these sites right from the time he was in class 7th make me feel about their utility. My son's Facebook attraction, which was always a point of confrontation among us, took a U turn when there social networking sites give useful information regarding his future life ahead. This also makes the interested in these sites and their actual functionality. Use of internet has become a part of everyone's life. Students too have their own phones which have all internet facility with different social networking sites and apps. There is a list of some social networking sites that come into existence instantly and are really very helpful.

\section{SOCIAL MEDIA - A BOON OR A CURSE FOR SOCIETY}

Over the last decade the popularity of social networking sites has risen to a massive scale. People seem to be in love of the idea of communicating with each other through pictures, videos, messages and voice mails than talking face to face. It was mostly teenagers and young adults who used the social media but now, even our grandparents are catching up with the trend of following celebrities on Twitter and regularly updating their profile pictures on Facebook. Nowadays, most us hours on popular social media sites like Facebook, Twitter, Myspace, etc. Our private space has been invaded by social media; there are very few things that others cannot find out about us with a click. Similar to the characteristics of a young child who wants a new toy after he gets bored of playing with the old ones, the youth is also looking for new things to keep themselves busy and discard anything that is outdated. Hence, the changing trend of social media! Earlier, a social networking website like Orkut was a fad amongst the youth. But slowly the interest of the youth developed and they wanted something new, that is when Mark Zuckerberg saw an opportunity in the social media market and invented a new 
social networking website called Facebook, taking the world by storm.[3] His website gained popularity like an epidemic, making other social networking websites bite the dust. Now Orkut is closed and we have so many other websites even.

\section{Use of Social Media for Academic Purpose}

Social media is a platform where the youth can form groups and discuss upon various topics ranging from music to education and politics to films. It is also an opportunity for young entrepreneurs to market their business ideas and promote them by creating a page. This helps the youth in building connections and opportunities for their career. One can showcase their talents here as well!

But every medal has its own reverse. So, there are some cons of using the social networking sites too.

The internet is a place to interact with new people and a way to expose you to strangers. One should be cautious while using social media. There are risks of account being hacked by someone else and they can pretend by stealing identity in the virtual world.

People often create fake profiles of themselves and put display pictures of famous personalities. Many predators and sexual offenders are also found using social networking sites. They trick others into believing that they are trustworthy but instead deceive innocent people who are easy targets, especially young children.

This gives rise to crime and provides an opportunity for perverts and pedophiles to look for vulnerable victims on the internet. As most teenagers and young adults are looking to make new friends on social media, they are not exposed to the real world. They are unaware of the fact that it is a cruel world where people often take advantage of others for their own benefit. Parents should be careful regarding such matters and keep a check on what their children are up to.

Though social media has revolutionized the world by bringing us closer than ever, it should be used to stay connected with our family and friends i.e. for necessary conversations.

The future of social networking sites look promising but people will have to deal with the problems associated with it. When we talk about social media, the first thing that strikes in our mid is Facebook or Twitter, but social media is very broader than this. Now, in the modern world social media is define in a terms of mobile and web based technologies to create a social network in a virtual world through a collection of online communication channels. [4] Social media is those virtual worlds where people interact freely, sharing and discussing ideas and information, know about each other and their lives, sending messages etc. by using a multimedia mix of personal words, pictures, videos and audios. We can use

- Blogs and Microblogs (as Twitter)

- Social news networking sites

- Content communities (as YouTube)

- Social networking sites (as Facebook)

- Collaborative projects (as Wikipedia)

Social media is different from any other media in many ways including quality, reach, frequency, usability, immediacy and durability. Let's take about the brief history of Social Media.[5] Social media is around us since the ancient times when first time humans began to talk; its evidences are still on the walls of caves in the form of wall paintings such as Ajanta, Ellora. After the development of electronic computers in 1950s, internet came into existence. In 1969, Computers were the first major commercial Internet Service provider for the public in U.S. The first email was delivered in 1971. The American Online (AOL) service opened in 1985. In 1998, Google became popular as a major internet search engine. In 2001, Wikipedia started as an online encyclopedia and it has completely revolutionized the teaching learning pattern. In 2003, Myspace and LinkedIn were launched as social networking sites. In 2004, Facebook, another social networking site came into existence.

Here are some spectacular examples of social media:-

Facebook:- The most popular free social networking site where registered users can find friends and keep in touch with friends, family and colleagues, upload photos and videos, share information, messaging etc.

Twitter: - It is a free microblogging site where registered members can post blogs called tweets and other members follow their tweets.

Wikipedia: - It is a free online Encyclopedia where anyone can register and create article for publication. Anyone can edit its content. It gives information on every subject.

LinkedIn: - It is a popular social networking site among business community and professional. They use it to get linked with other professionals.

Reddit: - It is a social news website and forum which gives all latest information.

Pinterest: - It is a social photo sharing website where users can create and manage image collections such as events, interest and hobbies. These sites are popular in demand and people are using them.

\section{Possible Advantages And Disadvantages of Social MEDIA}

\section{Advantages:}

a) Students can produce and retain information.

b) Social media offers lots of opportunities for learning and interaction.

c) Students are getting to explore and experience the world not only by books and assignments; but also by adapting social media.

d) In today's world; contacts, networks and communications are very important; students who are accessing Facebook, twitter and other such social networking site to connect and share information have good contacts.

e) Comfortable way of communication for shy teens. This can boost their self-esteem and confidence.

f) Social media gives teens with unusual interest and hobbies a place to share information and enthusiasm.

g) Social media helps them to enrich and manage their social lives. 
h) Teens who are differently abled and have other challenges can communicate with other teens with similar problems.[6]

\section{Disadvantages:}

a) Social media can be a very distracting and harmful for students.

b) Students share personal information, comment on someone's post which may be harmful for them.

c) Always glued with their mobiles, tablets, computer which is wastage of time and may spoil their performance.

d) Online bullying and harassment which is also known as Cyber-bullying may be the biggest danger for teens.

e) Online predators, it is basically an online sex crime against minors.

f) Less interaction with friends and family.

\section{Suggestive Social Networks for Students to Get ACADEMIC HELP}

With the growing use of social networking sites like Facebook and twitter, the methodology of education for students is finding new and improved ways. Students are getting more prone to the commodities and information these platforms offer.[7] Therefore this advancement in social networking platforms is providing students with much better options to engage with their contemporaries, enhance their skills and access a wide variety of academic tools and resources which will most definitely add up to their convenience. Enlisted below are a few social networking platforms that offer a wide variety of student friendly tools and assistance to help them academically.

1. Docsity: Docsity is a free social learning network for university and high-school students. It offers a platform for its users where they can engage in activities like sharing study related materials, counselling or simply connecting through a vast network of existing users from around the globe. Within the small timespan of two years, more than 6 , 00,000 students registered for the website and they use the website on daily basis. The website offers user generated contents in 7 different languages as Italian, English, Spanish, Polish, Russian, Serbian and Portuguese. Docsity also has its free application available for all android and iOS devices. The website also has a dedicated 24/7 support team to assist the students in their matters. This website is in great use abroad. We can ask our peers and students to use it even in India.

2. Study Blue: This website provides its student with a different approach towards studies. It offers an interactive way of studying where students get to create and animate flashcards.[8] The website currently has about 1.5 million study contents and also conducts different quizzical campaigns for the students and tracks the progress of its users.

3. Chegg: If Mathematics is troubling students and they need special assistance in any course, or want to gain more knowledge, Chegg is the answer to all queries. Chegg offers a very interactive way to the students looking for answers to the distressing questions. They can ask questions directly from the academic experts through vast network. It also offers a unique service to connect its users to their friends on Facebook.

4. Lynda: Lynda is also a very renowned website worldwide. It offers a huge variety of study material and online video tutorials that help students to learn different software, languages, business, creative skills and much more. Lynda's tutorials are well known for their quality and are equally helping for the learners.

5. Sophia: - Sophia offers a unique interaction because it builds a strong connection between students and renowned teachers from around the world. Sophia offers a number of free tools and services to the teachers, which literally transforms the way of teaching and helps in the provision of superior quality of services to students. The website is suitable for students of all ages, either middle school or an undergrad, Sophia has stored a lot more for its users to achieve their educational goals.

The advancements in technology have always proven to be beneficial for students. And with social networking platforms advancing, they are playing their role to facilitate the students with their needs. The above mentioned websites are in great use and imparting and sharing great chunk of knowledge.

\section{SOCIAL MEDIA's CONTRIBUTION TO SOCIETY}

The advancements in technology have always proven to be beneficial for students. And with social networking platforms advancing, they are playing their role to facilitate the students with their needs.

1) A boon in crisis: During "Superstorm Sandy" in U.S. social media played a vital role when many people used Facebook to give details of destruction and safeguard to their friends and relative.[9] Even sometimes in effort to clear phone lines, administration asked people to use social media for communication. Even Police can investigate gang-related crimes on social media networks.

2) A form of political influence: Social media is voice of people. Social media is a powerful force for social change and has potential to influence the outcome of political decisions.

3) Wiped-out the distance: We can reconnect with our students and alumni now living internationally without wasting money on international phone calls by using emails and video calls.

4) A revolution in brand making: Social media has transformed the market too. Brands have the ability to engage the customers with products, social media helps to make good brand image.[10] People use social media religiously and worship sites like a God, without processing any social media site they don't begin their day whether it is for personal communication, self-promotion or marketing. Human nature is quiet complex as they are habitual and willful even impatient. Due to these traits social media is flourishing day by day. Technological advancements made things easier for people to express 
themselves through social media platforms but a coin has two sides, still there are many people who focus on the negative effects of social media and argue against the good.

\section{CONCLUSION}

The biggest gifts that mankind has got is technology and more so, it is the information technology that has brought this world closer. While growth, development and speed of progress have increased due to this, a special bonding is happening between human beings. [11] This is through the social networking. Well, internet has got many social networking sites like Facebook, Twitter etc. and this has become the special platform for strangers to become friends or as a powerful tool of communication. But sometimes a question haunt- is social networking really a boon or bane in the case of today's young students? Yes, there is no doubt that this helps increase in friend circle, opportunity to interact with different people and make new friends across the world. But many are asking if the social networking sites are indeed being used for such productive reasons. There has been an increasingly disturbing behavior found in students and youngsters after their exposure towards such sites. Their interaction with family members, their concentration towards studies, and their interest in outdoor activities have come down drastically. Moreover, youngsters are being lured by conmen and other shady individuals through these sites and this is leading to grave risk. A recent incident of a student committing suicide after knowing about her boyfriend through a social networking site is a clear example of how extreme things can become. These incidents are happening everywhere nearly every day. The experts are suggesting that using of social networking is not wrong but the way it is being used is important. Students and youngsters must be given guidance on dos and don'ts. Also, the students must be educated on the overall developmental activities instead of getting glued to the mobile phones and computers and spending precious time chatting. [12] Students from their end must take initiative to find out how best such sites can be used. So friends, wake up and use technology as a boon and not a bane. Technology can serve as a good servant but when we try students to take help of these social networking sites but try to use them as helping tool not as their main stream knowledge bank.

\section{REFERENCES}

[1] E. Adams, H. Morrison, and J. Reddy, "Conversation with a computer as a technique of language instruction,” MLJ, vol. 52, pp. 3-16, 1968.

[2] D. M. Bell. (February 23, 2003). TV news in the EFL/ESL classroom: Criteria for selection. TESL-EJ. [Online]. 7(3). pp. 1-17. Available: http://wwwwriting.berkeley.edu/TESL-EJ/ej27/a2.html

[3] D. Brinton and W. Gaskill, "Using news broadcast in EFL/ESL classroom,” TESOL Quarterly, vol. 12, no. 2, pp. 403-415, 1978.

[4] H. B. Douglas, Principles of Language Learning and Teaching, 4th ed. Addison Wesley Longman. Inc., 2000.

[5] R. M. Cauldwell, "Direct encounters with fast speech on CD Audio to teach listening,” System, vol. 24, no. 4, pp. 521-528, 1996.

[6] H. Keller, "Pedagogical wishes for a machine dictionary: An example from Russia,” MLJ, vol. 71, pp. 12-17, 1987.

[7] H. Decker, "Computer-aided instruction in French sytax," MLJ, vol. 60, pp. 263-273, 1976

[8] S. Krashen, Language Acquisition and Language Education, Prentice Hall International, New York, 1981.

[9] S. K. Folse, "Myths about teaching and learning second language vocabulary, what recent research says,” TESL Reporter, vol. 37, no. 2, pp. 1-13, 2004.

[10] M. Saville-Troike, Introducing Second Language Acquisition, New York: Cambridge University Press, 2012

[11] S. Silberstein, Techniques and Resources in Teaching Reading, New York: Oxford University Press, 1994.

[12] C. Evans, Using TV News to Integrate the Four Skills: A Guide for EFL Teachers, 2006.

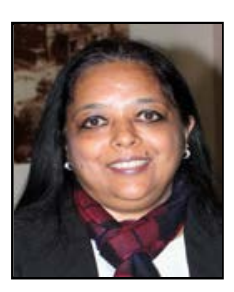

Reena Mittal is an associate professor in the D.A.K. Degree College, Moradabad, Uttar Pradesh, India. She has been lucky to have 28 papers published in reputed national and international Journals with ISSN. She has attended nearly 39 seminars and workshops actively and enthusiastically while presenting papers in almost all of them. She recently went to the Oxford University, UK for a 15 day summer seminar in English language teaching and represented her country, India. It was a life time experience learning techniques of English teaching for her and she plans to bring changes to the current language teaching techniques starting with her college and university. This year she has contributed with an edited book on easy strategies for learning English. She is an enthusiastic teacher, and she is very popular among her students for her friendly yet disciplined behavior. 